$\begin{array}{rr}\text { JURNAL } & \text { Volume } 12, \text { Nomor } 1, \text { Januari } 2016 \\ \text { FIT(1)PATOLOGI } & \text { Halaman } 34-37 \\ \text { I N D O N E S I } & \text { DOI: } 10.14692 / \text { jfi.12.1.34 } \\ \text { ISSN: } 0215-7950 & \end{array}$

KOMUNIKASI SINGKAT

\title{
Tingkat Infestasi Aphelenchoides besseyi pada Benih Padi di Bogor
}

\section{Infestation Level of Aphelenchoides besseyi on Seed Rice in Bogor}

\author{
Fitrianingrum Kurniawati dan Supramana* \\ Institut Pertanian Bogor, Bogor 16680
}

\begin{abstract}
ABSTRAK
Penyakit pucuk putih (white tip) pada tanaman padi telah ditemukan di wilayah Kabupaten Bogor, antara lain di Sukamakmur, Petir, dan Kebun Percobaan Muara. Bagian pucuk daun tanaman sakit berwarna putih sepanjang 3-5 cm, nekrosis, terpilin, dan mengerut. Penyakit ini disebabkan oleh nematoda Aphelenchoides besseyi dan bersifat tular benih. Ekstraksi nematoda berdasarkan standar ISTA dilakukan terhadap benih padi yang diperoleh dari kios pertanian di Bogor dan Kebun Percobaan Muara. Delapan varietas yang diamati ialah SL8SHS, hibrida padi sawah (HIPA14), IPB 3S, IR-64, Pertiwi (Pak Tiwi), Inpari 31, Pandan Wangi Bogor (Sintanur) dan Ciherang. Nematoda yang ditemukan umumnya ialah nematoda betina dengan ciri-ciri morfologi $A$. besseyi, sehingga disimpulkan bahwa $A$. besseyi berasosiasi dengan benih padi uji tersebut. Semua benih varietas padi yang diamati mengandung A. besseyi dengan jumlah berkisar 3-341 ekor per $5 \mathrm{~g}$ benih.
\end{abstract}

Kata kunci: nematoda parasit, penyakit pucuk putih, tular benih

\begin{abstract}
The white tip disease on rice plants have been discovered in the district of Bogor, i.e. in Sukamakmur, Petir, and Muara Experimental Station areas. The infected plant exhibited symptoms, involving whiten leaf tip 3-5 cm that later turn to necrosis, twisted and crinkled. The disease is supposed caused by a parasitic nematode, namely Aphelenchoides besseyi, which is known seed borne. Extraction of nematodes based on ISTA protocols on rice was conducted. Seeds from eight varieties, SL8SHS, Hybrid Rice (HIPA14), IPB 3S, IR-64, Pertiwi (Pak Tiwi), Inpari 31, Pandan Wangi Bogor (Sintanur) and Ciherang, was obtained from seed vendors in Bogor and Muara Experimental Station. The majority of nematodes recovered were females and only few males with morphological characteristics matching with $A$. besseyi. All seed rice varieties tested contained $A$. besseyi with the average of 3-341 nematodes per $5 \mathrm{~g}$ seed.
\end{abstract}

Key words: parasitic nematodes, seed-borne, white tip disease

*Alamat penulis korespondensi: Laboratorium Nematologi Tumbuhan, Departemen Proteksi Tanaman, Fakultas Pertanian, Institut Pertanian Bogor. Jalan Kamper Darmaga, Bogor 16680.

Tel: 0251-8629364, Faks: 0251-8629362, Surel:supramana@ipb.ac.id 
Penyakit pucuk putih (white tip) merupakan penyakit baru pada tanaman padi di Indonesia. Penyakit ini disebabkan oleh nematoda Aphelenchoides besseyi. $A$. besseyi menyerang bagian tajuk tanaman sehingga nematoda ini sering disebut sebagai foliar nematode. Selain sebagai parasit tajuk, A. besseyi juga merupakan nematoda terbawa benih yang dapat bertahan pada benih dalam kondisi anhidrobiosis selama penyimpanan di gudang (Tiwari dan Khare 2003). Nematoda ini bersifat ektoparasit. Penyakit pucuk putih ini bersifat tular benih. Nematoda ini masuk ke dalam bunga padi, bertahan di bawah seed glumes sebagai nematoda dewasa atau juvenil stadium empat, dan mengganggu perkembangan tanaman inangnya (Nandakumar et al. 1975; Hollis dan Keoboonrueng 1984). Akibatnya daundaun yang terserang mengalami perubahan bentuk dan batang menjadi kerdil. Ujung daun kehilangan klorofil sehingga penyakitnya disebut dengan pucuk putih.

Penyakit pucuk putih pertama kali dilaporkan oleh Dastur di India pada tahun 1936. Infeksi $A$. besseyi dapat menyebabkan kehilangan hasil sebesar $18.8 \%$ dan $43 \%$ pada tahun 2007 dan 2008 di Turki (Tulek dan Cobanoglu 2010), 50\% di Brazil (DaSilva 1992), dan 30-50\% di China (Wang et al. 2004). Penyakit ini telah ditemukan menyerang tanaman padi di beberapa negara (Fortuner dan Williams 1975; Duncan dan Moens 2006). A. besseyi juga telah dilaporkan menyerang tanaman padi sawah di Iran Utara (Jamali et al. 2007). Menurut Balai Besar Karantina Pertanian (BBKP) Soekarno Hatta (2013) A. besseyi tergolong sebagai organisme pengganggu tanaman karantina (OPTK) golongan A2 di Indonesia. Penyakit ini telah ditemukan di beberapa daerah di Indonesia khususnya Kabupaten Bogor, Jawa Barat. Oleh karena itu, perlu dilakukan survei keberadaan penyakit pucuk putih di Indonesia untuk mengetahui lebih jelas distribusi dari penyakit ini di lapangan.

Gejala penyakit pucuk putih pada daun padi ialah bagian pucuk daun berwarna putih sepanjang 3-5 cm, pada tahap lebih lanjut bagian tersebut menjadi nekrosis, pucuk daun membelit dan mengerut, distorsi pada daun bendera. Malai menjadi lebih pendek, jumlah bulir berkurang, dan jumlah bulir hampa menjadi banyak. Gejala ini ditemukan dibeberapa wilayah di Kabupaten Bogor: Sukamakmur, Petir, dan Kebun Percobaan (KP) Muara (Gambar 1).

Sebanyak $5 \mathrm{~g}$ benih padi varietas SL8SHS, HIPA14, IPB3S, IR-64, Pertiwi, Inpari 31, Pandan Wangi Bogor, dan Ciherang diekstraksi nematodanya berdasarkan standar ISTA (2014) yang dimodifikasi. Benih padi tersebut berasal dari kios pertanian di Bogor dan KP Muara. Benih padi 8 varietas tersebut dipotong bagian hilumnya, diletakkan di atas saringan nilon dengan diameter mata saringan $0.25 \mathrm{~mm}$, kemudian diberi air hingga benih terendam, dan selanjutnya diinkubasi 24 jam pada suhu sekitar $25{ }^{\circ} \mathrm{C}$. Setelah 24 jam, air hasil ekstraksi disaring dengan saringan 500 mesh dan disimpan dalam tabung koleksi untuk diamati menggunakan mikroskop stereo.

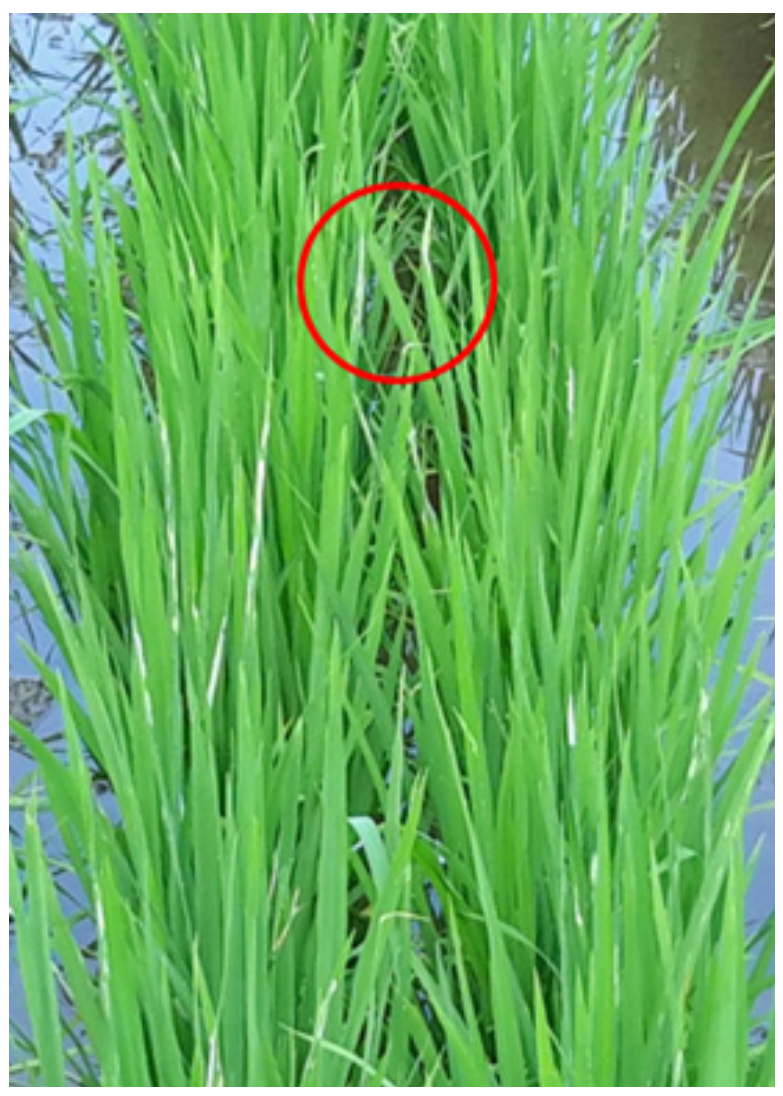

Gambar 1 Gejala penyakit pucuk putih (white tip) pada padi varietas IPB $3 \mathrm{~S}$ di lapangan. 
Semua varietas padi yang diamati mengandung nematoda. Ciri-ciri morfologinya sebagai berikut: tubuh ramping berbentuk seperti cacing (vermiform), panjang tubuh $0.5-0.8 \mathrm{~mm}$, anulasi halus, bibir set off, stilet pendek seperti tombak (spear), kelenjar esofagus tumpang tindih dan mempunyai bulbus median yang besar, berbentuk oval. Nematoda betina mempunyai vulva yang terletak $60-75 \%$ dari panjang badan (didelfik), ekor betina meruncing berbentuk conoid dengan ujung ekor terdapat tonjolan (mukro) sebanyak 2-4 titik. Tubuh nematoda jantan bagian posterior melengkung hingga $180^{\circ}$, ekor berbentuk conoid dengan 2-4 mucro, dan mempunyai spikula berbentuk seperti

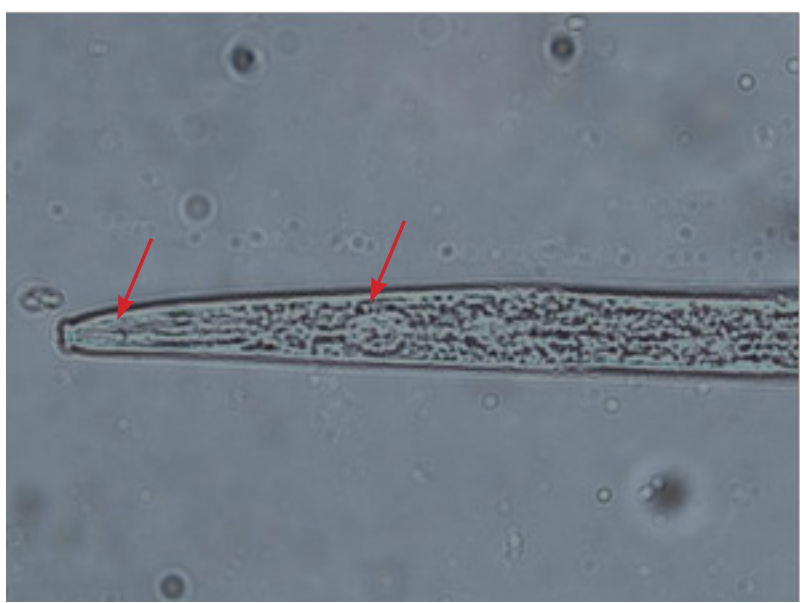

a

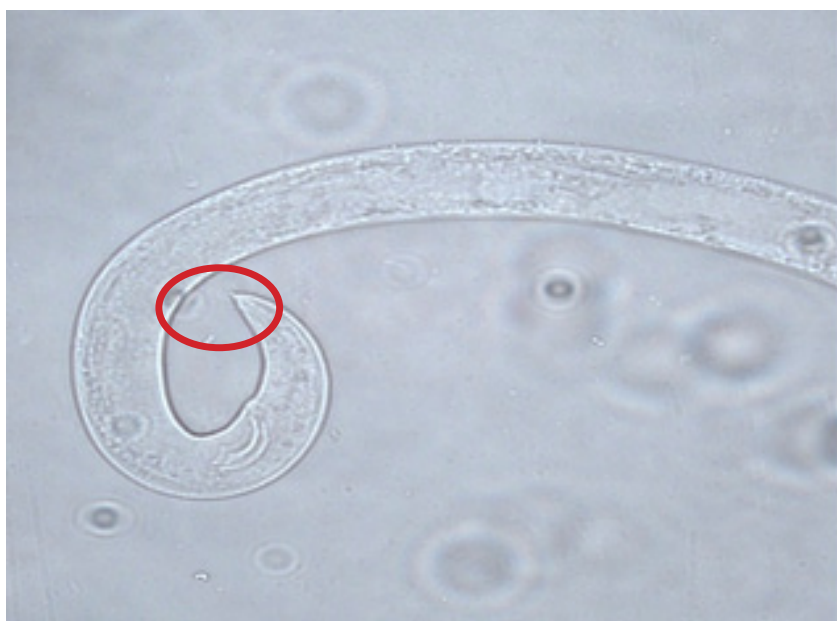

c duri (thorn-shaped spicules). Ciri-ciri tersebut sesuai dengan $A$. besseyi (OEPP/EPPO 2004)

(Gambar 2) sehingga varietas benih padi yang diamati ini sudah terinfeksi nematoda. Jumlah $A$. besseyi yang diperoleh rata-rata berkisar 3-341 ekor per $5 \mathrm{~g}$ benih.

\section{DAFTAR PUSTAKA}

[BBKP] Balai Besar Karantina Pertanian Soekarno Hatta. 2013. Laporan Tahunan 2013 BBKP Soekarno Hatta. Jakarta(ID): BBKP. hlm: 1-92.

Da-Silva GS. 1992. White tip and national rice production. Informe Agropecuario Belo Horizonte. 16:57-59.

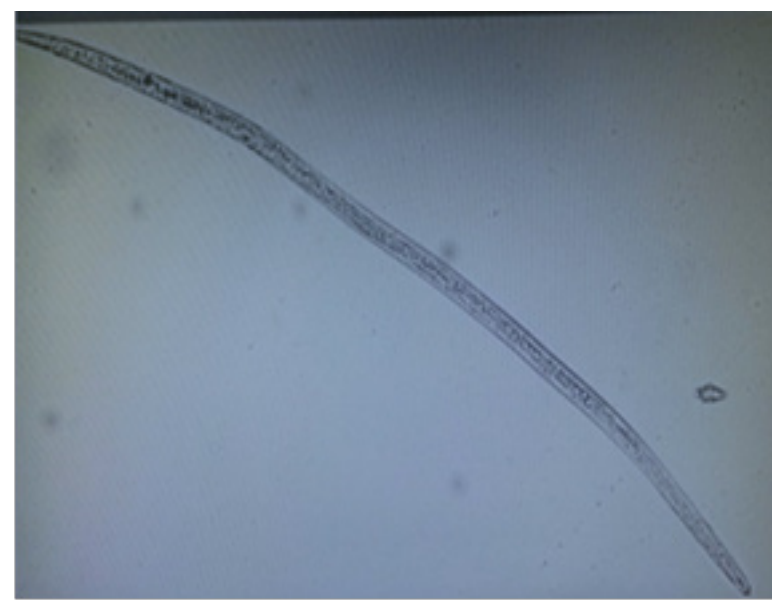

b

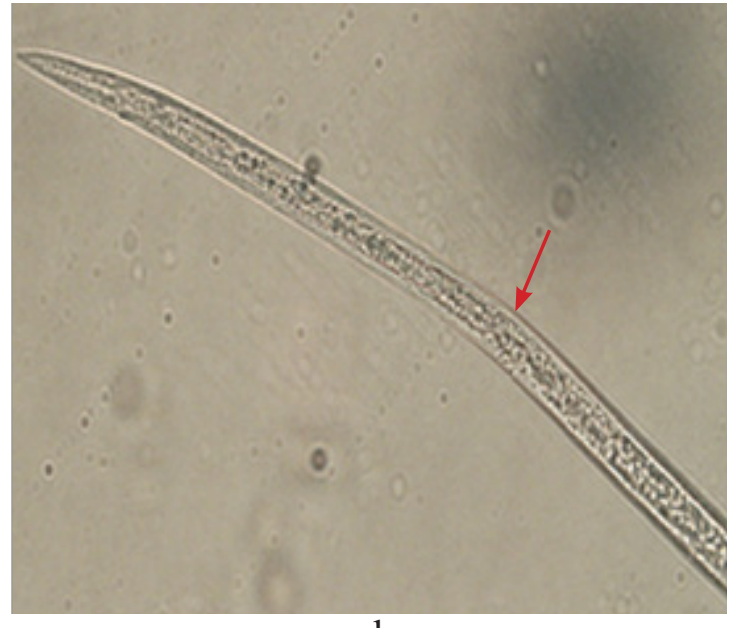

d

Gambar 2 Ciri morfologi nematoda Aphelenchoides besseyi pada benih padi: a, bagian anterior dengan stilet berbentuk seperti tombak dan terdapat bulbus median yang berukuran besar, berbentuk oval; b, nematoda betina seluruh tubuh; c, tubuh nematoda jantan bagian posterior melengkung hingga $180^{\circ}$, dengan spikula seperti duri (thorne shaped spicule) dan; d, vulva betina dengan tipe didelfik yang terletak $60-75 \%$ panjang tubuhnya. 
Duncan LW, Moens M. 2006. Migratory endoparasitic nematodes. Di dalam: Perry RN, Moens M, editor. Plant Nematology. Wallingford, Oxfordshire (UK): CABI. hlm: 123-152. DOI: http://dx.doi. org/10.1079/9781845930561.0123.

Fortuner R, Williams KJO. 1975. Review of literature on Aphelenchoides besseyi Christie, 1942, the nematode causing "white tip" disease in rice. Helminthological abstracts Series B. Plant Nematology. 44(1):1-40.

Hollis JP, Keoboonrueng S. 1984. Nematode parasites of rice. Di dalam: Nickle WR, editor. Plant And Insect Nematodes. New York (US): Marcel Dekker. hlm: 95-146.

[ISTA] International Seed Testing Association. 2014. Detection of Aphelenchoides besseyi on Oryza sativa. Annexe to chapter 7: Seed health methods 7-025. Switzerland $(\mathrm{CH})$ : International seed testing Association. hlm: 1-6.

Jamali S, Pourjam E, Alizadeh A, Alinia F, Futai K. 2007. White tip disease of rice in Iran. Di dalam: Proceedings of The Fourth Temperate Rice Conference; 2007 June 25-28; Novara (IT). hlm: 32-33.
Nandakumar C, Prasad SJ, Rao SY, Rao J. 1975. Investigations on the whitetip nematode (Aphelenchoides besseyi Christie, 1942) of rice (Oryza sativa L.). Indian J Nematol. 5:62-69.

OEPP/EPPO. 2004. EPPO Standards PM 7/39 Aphelenchoides besseyi-diagnostic protocols for regulated pests. Bull OEPP/ EPPO. 34:303- 308. DOI: http://dx.doi. org/10.1111/j.1365-2338.2004.00733.x.

Tiwari SP, Khare MN. 2003. White tip caused by Aphelenchoides besseyi, an important seed borne disease of rice. Di dalam: Trivedi PC, editors. Advances in Nematology. Jodhpur (IN): Scientific Publisher. hlm: 103-114.

Tulek A, Cobanoglu S. 2010. Distribution of the rice white tip nematode, Aphelenchoides besseyi, in rice growing areas in Thrace Region of Turkey. Nematologica Mediteranea. 38:215-217.

Wang ZM, Zhou FM, Lu YL, Lu HF, Chen ZY, Liu YF, Wei W. 2004. Study on causes and control measures of small grains and erect ears in rice in Jiangsu Province. Jiangsu Agric Sci. 3:33-38. 